\title{
Peripheral endocannabinoids regulate skeletal muscle development and maintenance
}

\author{
Dongjiao Zhao (1), Amber Pond (1), Bruce Watkins (2), Dave Gerrard (3), Yefei Wen
} (4), Shihuan Kuang (4), Kevin Hannon (1)

(1) Department of Basic Medical Sciences, Purdue University, West Lafayette, IN; (2) Department of Food Sciences, Purdue University, West Lafayette, IN; (3) Department of Animal Sciences, Virginia Tech University, Blacksburg, VA; (4) Department of Animal Sciences, Purdue University, West Lafayette, IN, USA.

\begin{abstract}
As a principal tissue responsible for insulin-mediated glucose uptake, skeletal muscle is important for whole-body health. The role of peripheral endocannabinoids as regulators of skeletal muscle metabolism has recently gained a lot of interest, as endocannabinoid system disorders could cause peripheral insulin resistance. We investigated the role of the peripheral endocannabinoid system in skeletal muscle development and maintenance. Cultures of $\mathrm{C} 2 \mathrm{C} 12$ cells, primary satellite cells and mouse skeletal muscle single fibers were used as model systems for our studies. We found an increase in cannabinoid receptor type 1 (CB1) mRNA and endocannabinoid synthetic enzyme mRNA skeletal muscle cells during differentiation. We also found that activation of CB1 inhibited myoblast differentiation, expanded the number of satellite cells, and stimulated the fast-muscle oxidative phenotype. Our findings contribute to understanding of the role of the endocannabinoid system in skeletal muscle metabolism and muscle oxygen consumption, and also help to explain the effects of the peripheral endocannabinoid system on whole-body energy balance.
\end{abstract}

Key Words: Endocannabinoids, skeletal muscle, development, differentiation, metabolism

European Journal Translational Myology 2010; 1 (4): 167-179

The endocannabinoid system (ECS) is a complex network that regulates a variety of physiological processes including appetite, energy homeostasis, body weight, drug addiction, pain-sensation, mood, and memory $[2,7,11,15,26,28,29,39]$. The endocannabinoid system comprises a group of neuromodulatory lipids, including anandamide (AEA) and 2arachidonoylglycerol (2-AG) [31,39], and their receptors, the cannabinoid receptors type 1 (CB1) and 2 (CB2). Endocannabinoids are derivatives of arachidonic acid conjugated with ethanolamine or glycerol [21,37]. Signals induced by the endocannabinoids are terminated rapidly by transporter-mediated uptake [3] and subsequent degradation [4,14]. Anandamide is released from a membrane lipid precursor, NAPE ( $\mathrm{N}$-arachidonoylphosphatidylethanolamine) [32] and is catalyzed by NAPE phospholipase D (NAPE-PLD) [32]. The degradation of AEA is performed by a specific enzyme, fatty acid amide hydrolase (FAAH) [10]. Diacylglycerol lipase $\alpha$ (DAGL $\alpha)$ is essential for 2-AG synthesis $[36,43]$ and $2-A G$ is degraded by monoacylglyceride lipase (MAGL) [16].

It is known that the endocannabinoid system is involved in metabolic regulation and glycemic control. For example, in the obese state the endocannabinoid system is overactivated. Further, studies of both genetically and diet-induced obese animal models studies determined elevated levels of endocannabinoids in the hypothalamus and peripheral tissues $[9,12,18,26]$. In obese or type 2 diabetic patients, circulating levels of AEA and 2-AG are increased and levels of $2-\mathrm{AG}$ are elevated in visceral adipose tissue [12]. Further, CB1 gene knockout $(\mathrm{Cnr}-/-)$ mice were resistant to diet-induced obesity and remain lean [33].

Skeletal muscle plays an important role in metabolic regulation and glycemic control $[6,24,35]$. It is likely that skeletal muscle exerts these effects though the endocannabinoid system, however this has not been studied in sufficient detail. CB1 receptors have been detected in skeletal muscle [30] and studies suggest that blockade of $\mathrm{CB} 1$ may have direct effects on 


\section{Endocannabinoids regulate skeletal muscle}

European Journal Translational Myology 2010; 1 (4): 167-179

skeletal muscle by modulating energy homeostasis [8,33]. For example, glucose uptake and oxygen consumption were significantly increased in the isolated soleus of mice treated for 7 days with the CB1 antagonist SR141716 compared with control mice [33]. Further, expression of CB1 mRNA in soleus muscle from obese mice was increased compared with soleus muscle from lean mice [30]. All these findings suggest that $\mathrm{CB} 1$ plays an important role in skeletal muscle metabolism, especially in glucose uptake $[30,33]$. Currently, data on the effects of the ECS on skeletal muscle are much less than for other tissues. The purpose of this study was to investigate the involvement of the peripheral endocannabinoid system on skeletal muscle development and establishment of metabolic function.

\section{Materials and Methods}

\section{Pharmacological reagents}

$R(+)$-methanandamide (MAEA) was purchased from Sigma-Aldrich Chemical Co (St. Louis, MO, USA). AM-251 was purchased from Enzo (Plymouth Meeting, PA, USA). Trypsin was purchased from Gibco Invitrogen (Carlsbad, CA, USA). Tissue Tek was purchased from Fisher Scientific (Houston, TX, USA).

\section{Animals}

The Male NIH Swiss mice were purchased from Harlan Labs (Indianapolis, IN, USA). Animal care procedures followed approved Purdue Animal Care and Use Committee (PACUC) protocols.

\section{C2C12 cell culture}

In Mouse $\mathrm{C} 2 \mathrm{C} 12$ myoblasts were maintained in DMEM supplemented with $10 \%$ fetal bovine serum, $0.1 \%$ gentamicin reagent and $1 \%$ antibiotic antimycotic at $37^{\circ} \mathrm{C}$ and $5 \% \quad \mathrm{CO} 2$. Differentiation medium contained $2 \%$ horse serum instead of $10 \%$ fetal bovine serum. When cells reached $70 \%$ confluence they were passaged by trypsinization $(0.5 \%$ trypsin in $0.5 \mathrm{mM}$ EDTA [Invitrogen, Carlsbad, CA, USA]).

\section{GIEMSA staining to assay differentiation}

Cells were fixed in $100 \%$ methanol for $5 \mathrm{~min}$ and subsequently rinsed with PBS. Cells were then stained with a fresh solution of $10 \%$ Giemsa (Invitrogen, Carlsbad, CA, USA) in PBS at room temperature for $10 \mathrm{~min}$ and then rinsed in PBS for $10 \mathrm{~min}$. For each treatment depicted, 6 random images were captured from each culture using a Leaf Micro-Lumina scanning digital camera. From these images, the following data were obtained: total cell number; number of myofibers (cells with greater than or equal to 3 nuclei); number of nuclei per myofiber (\# of nuclei in a cell containing 3 or more nuclei) Cells were fixed in $100 \%$ methanol for $5 \mathrm{~min}$ and subsequently rinsed with PBS. Cells were then stained with a fresh solution of $10 \%$ Giemsa
(Invitrogen, Carlsbad, CA, USA) in PBS at room temperature for $10 \mathrm{~min}$ and then rinsed in PBS for 10 min. For each treatment depicted, 6 random images were captured from each culture using a Leaf MicroLumina scanning digital camera. From these images, the following data were obtained: total cell number; number of myofibers (cells with greater than or equal to 3 nuclei); number of nuclei per myofiber (\# of nuclei in a cell containing 3 or more nuclei).

\section{Real time PCR (RT-PCR)}

Total RNA was extracted from skeletal muscle using TriZol reagent according to the manufacturer's protocols (Life Technologies, Bethesda, MD, USA). The concentration and purity of the RNA were determined by measurement of the optical densities at 260 and $280 \mathrm{~nm}$ and analyzed by gel electrophoresis. Contaminating DNA was removed from total RNA by two 10-min treatments with RQ1 (RNA Qualified) RNase-Free DNase (Promega, Madison, WI, USA). The RNA solutions were diluted to a working concentration of $1 \mu \mathrm{g} / \mu \mathrm{l}$ in DEPC treated water $(0.1 \%$ DEPC to water, Invitrogen). cDNA was prepared from RNA samples as following: A $20 \mu \mathrm{l}$ reaction mix was made of 1x 1st standard buffer (Life Technologies), 10 $\mathrm{mM}$ DTT, $1 \mathrm{mM}$ dNTPs, and $5 \mu \mathrm{M}$ random hexamers. To this, $200 \mathrm{ng}$ of RNA were added and the mixtures were heated to $65^{\circ} \mathrm{C}$ for 10 minutes. The reactions were then cooled to $25^{\circ} \mathrm{C}$ for 5 minutes and $1 \mu \mathrm{l}(200$ units) superscript II Reverse Transcriptase (Invitrogen) was added. Identical reaction mixtures were made for each RNA sample without adding superscript II Reverse Transcriptase. These reactions served as noRT controls. The reaction was heated to $37^{\circ} \mathrm{C}$ for 90 min followed by heat deactivation at $90^{\circ} \mathrm{C}$ for $10 \mathrm{~min}$. The reaction was then diluted to $100 \mu \mathrm{l}$ with $\mathrm{H} 2 \mathrm{O}$ and stored at $-20^{\circ} \mathrm{C}$ for later use. RT-PCR was performed using a GeneAmp 5700 Sequence Detection System (PE Applied Biosystems, Carlsbad, CA, USA) and the SYBR Green PCR core reagents kit (PE Applied Biosystems). RT-PCR was performed using Integrated DNA Technologies, Inc. primers. Sequences of primers are shown in Table 1. Results are presented as a ratio of target gene mRNA/18S mRNA. Primers were designed using the Primer3 program (Geneious, Auckland, New Zealand) and reactions were performed using primers obtained from Integrated DNA Technologies Inc. (Coralville, IA, USA). Each pair of primers gave a product about $200 \mathrm{bp}$ and spanned an intron.

\section{Primary myoblast cell culture}

Forelimbs and hindlimbs were removed from neonatal mice (2-5 d old) and bones were dissected away. The remaining muscle mass was weighed. A few drops of PBS were added and the muscle was minced into a coarse slurry using razor blades. Cells were enzymatically dissociated by the addition of $2 \mathrm{ml}$ per $\mathrm{g}$ 
Table 1: Forward and reverse primers used in RT-PCR reactions.

\begin{tabular}{|l|l|l|}
\hline Genes & Forward primer $5-3$ & Reverse primer $5-3$ \\
\hline CB1 & CCTTGCAGATACAACCTT & TGCCATGTCTCCTTTGATA \\
\hline CB2 & CATAAGCCGATCTCTCCAA & CCAAAGCTGGTGCAGGAA \\
\hline MAGL & TGGCATGGTCCTGATTCACCTCT & TTCAGCAGCTGTATGCCAAAGCAC \\
\hline NAPE-PLD & ATGCAGAAATGTGGCTGCGAGAAC & ACCACCTTGGTTCATAAGCTCCGA \\
\hline DAGL-Alpha & AATTTGCGGACTTACAACCTGCGG & TCCCAGACAGGAAAGCCAAGATGT \\
\hline FAAH & TAGCTTGCCAGTATTGACCTGGCT & AGGAAGTAATCGGGAGGTGCCAAA \\
\hline 18S & CGGCTACCACATCCAAGGAA & GCTGGAATTACCGCGGCT \\
\hline
\end{tabular}

streptomycin. This suspension solution was pre-plated onto an uncoated plate and incubated for 1 hour. At the end of this incubation, the media and non-attached cells (primary myoblasts) were transferred onto a collagen-coated plate. These cells were maintained in Ham's complete growth medium at $37^{\circ} \mathrm{C}$ and $5 \% \mathrm{CO} 2$. The cells were passaged by trypsination $(0.5 \%$ trypsin in $0.5 \mathrm{mM}$ EDTA, Invitrogen) when cells reached $70 \%$ confluence. Differentiation medium was DMEM supplemented with $2 \%$ horse serum, $10 \mathrm{mM}$ Hepes, 100 $\mathrm{U} / \mathrm{ml}$ penicillin, and $100 \mathrm{mg} / \mathrm{ml}$ streptomycin.

\section{Isolated muscle fibers}

Extensor digitorum longus (EDL) muscles were dissected out by handling tendons so as not to damage the muscle fibers. Muscles were then placed in $0.2 \%$ collagenase and incubated in a shaking water bath at $35^{\circ} \mathrm{C}$ for $45 \mathrm{~min}$. After the fibers had been loosened by this treatment, they were liberated using heat polished glass Pasteur pipettes of various bore size and by viewing under a dissecting microscope. These fibers were transferred to DMEM (containing 10\% fetal bovine serum, $0.1 \%$ gentamicin reagent and $1 \%$ antibiotic antimycotic) at $37^{\circ} \mathrm{C}$ and $5 \% \mathrm{CO}_{2}$.

\section{Plasmids}

pcDNA3-CB1 was provided by Dr. Beat Lutz (Gutenberg-University Mainz Duesbergweg). $p c D N A 3$ was obtained from Invitrogen. The $p C M V-L a c Z$, Renilla luciferase ( $p R L-S V 40)$ and myoglobin promoter driven-luciferase reporter were obtained from Promega. Sarco(endo)plasmic reticulum calcium ATPase 1 (SERCA1; -1373 to $+172 \mathrm{bp}$ ) promoter driven-luciferase reporter was acquired from Dr. Steven Swoap (Williams College, Williamstown, MA, USA). Plasmids used in these studies were purified with an EndoFree plasmid mega kit (Qiagen, Alameda, CA, USA) and diluted in $0.9 \%$ saline to a final concentration of $0.5 \mu \mathrm{g} / \mu \mathrm{l}$.

\section{In vitro transfection}

For reporter gene experiments, reporter gene constructs were transfected into myoblasts using FuGene 6 (Roche Applied Science, Indianapolis, IN, USA) for 8 $\mathrm{h}$ according to the manufacturer's recommendations. The $p R L-S V 40$ plasmid expressing Renilla luciferase was cotransfected at a ratio of 1:50 to normalize mese muscies and reverse uranscrioed, and cinas were subjected to RT-PCR as described above. In another experiment, gastrocnemius, soleus and tibialis anterior muscles were dissected and pooled from 5 week old male mice. These muscles were used for RTPCR.

\section{In vivo DNA injection and electroporation}

Mice were anesthetized with an intraperitoneal injection of $0.01 \mathrm{ml} / \mathrm{g} \mathrm{BW}$ of a mixture of ketamine $(100 \mathrm{mg} / \mathrm{ml})$ and xylazine $(20 \mathrm{mg} / \mathrm{ml})$. Fifty $\mu \mathrm{l}$ of a mixture of $15 \mu \mathrm{g}$ of $p c D N A 3-C B 1,10 \mu \mathrm{g}$ of reporter gene (Sercal-luciferase or myoglobin-luciferase) [5, 44] and $1 \mu \mathrm{g}$ pRL-SV40 Renilla luciferase were injected into the gastrocnemius muscle. In the contralateral gastrocnemius muscle, $50 \mu \mathrm{l}$ of a mixture of 15 $\mu \mathrm{g}$ of empty $p c D N A 3,10 \mu \mathrm{g}$ reporter genes and $1 \mu \mathrm{g}$ $p R L-S V 40$ Renilla luciferase was injected. Following the injection, electroporation was performed (200 $\mathrm{V} / \mathrm{cm}, 8$ pulses, $1 \mathrm{~Hz}, 20 \mathrm{~ms}$ interval) using a BTX ECM 830 electroporator (BTX Harvard Apparatus, Holliston, MA) as described previously [1]. Four days following electroporation, muscles were dissected and homogenized in passive lysis buffer and analyzed with Dual Luciferase Assay Kit (Promega). All procedures were conducted in accordance with guidelines set by the Purdue Animal Care and Use Committee.

\section{Immunofluorescent staining}

Cells or muscle fibers were fixed by incubation with $4 \%$ paraformaldehyde in $\mathrm{PBS}, \mathrm{pH} 7.4$ at room temperature for 5-10 min. Prior to immunohistochemistry, tissue was blocked by incubation in 5\% normal horse serum/PBS for $30 \mathrm{~min}$ at room temperature. Primary antibodies were diluted in blocking buffer: MyoD (1:300, Santa Cruz Biotechnology, Santa Cruz, CA); Pax7 (1:70, Developmental Studies Hybridoma Bank, Iowa City, IA, USA). Samples were incubated in primary antibody solutions at room temp for $1 \mathrm{~h}$ or $4^{\circ} \mathrm{C}$ overnight. Secondary antibodies were diluted in PBS (1/1000 Alexa Fluor® 647 Conjugation; Invitrogen) and Alexa Fluor ${ }^{\circledR} 568$ Conjugation (Invitrogen). Samples were incubated in secondary antibody at room temp for 30-45 min. Nuclei were counterstained with $0.5 \mu \mathrm{g} / \mathrm{ml}$ DAPI (Sigma-Aldrich) in PBS for $5 \mathrm{~min}$. 
A

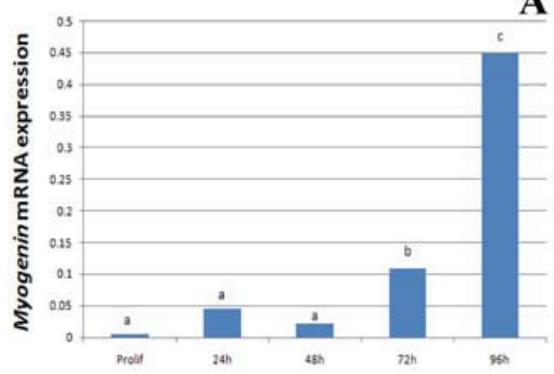

C

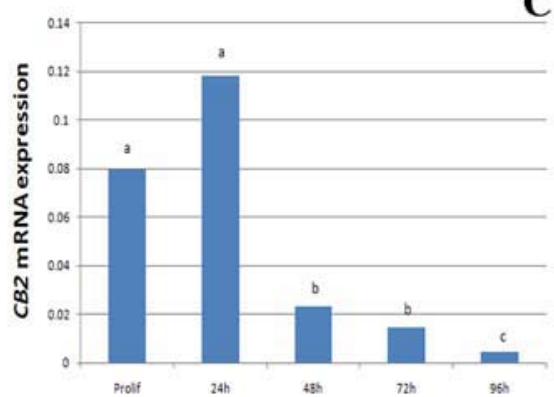

$\mathbf{E}$

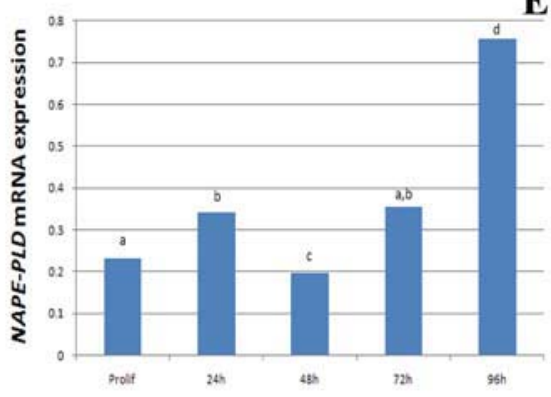

B

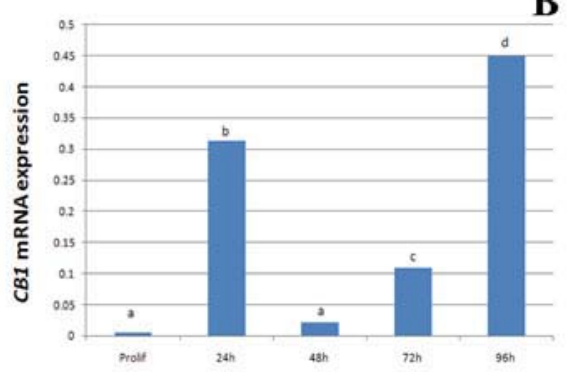

D

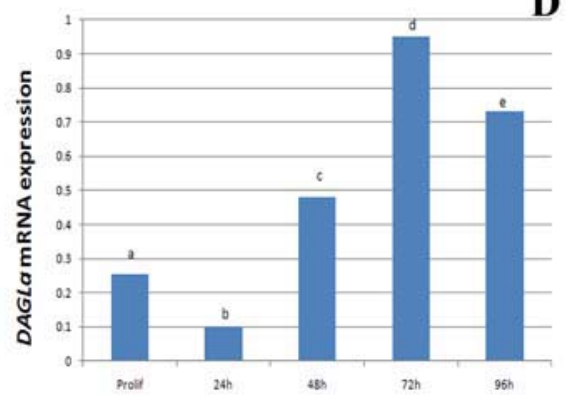

F

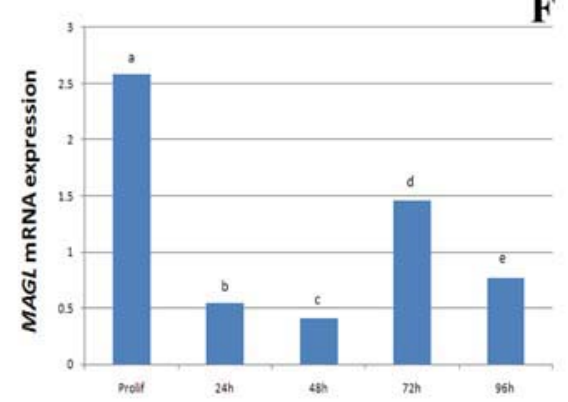

Fig 1. Endocannabinoid receptor $C B 1$ and endocannabinoid synthetic enzyme mRNAs increase during differentiation of C2C12 skeletal muscle cells. Total RNA was isolated from proliferating cells (Prolif) or cells differentiated for 24, 48, 72 or 96 hours. After reverse transcription, cDNAs were assayed by RT-PCR. A) Myogenin mRNA expression was detected in cells differentiated for 72 and $96 \mathrm{~h}$, demonstrating that terminal myofiber differentiation was occurring at these time points. (MSE=0.08); B) CB1 mRNA expression was significantly up-regulated 24, 72 and 96h post differentiation. (MSE=0.04);C) CB2 mRNA expression was significantly down-regulated upon terminal differentiation. (MSE =0.02); D) Endocannabinoid synthetic enzyme DAGLa expression was significantly increased upon C2C12 myofiber differentiation. (MSE=0.02); E) Endocannabinoid synthetic enzyme NAPE-PLD expression was significantly increased upon C2C12 myofiber differentiation. $(M S E=0.04) ; F)$ The expression of the endocannabinoid degradative enzyme MAGL was significantly decreased upon differentiation. (Mean Standard Error $[M S E]=0.06) . n=3$ for each mean. Means with different superscripts differ $(p<0.01)$.

\section{Statistics}

Data were analyzed by ANOVA using SAS. Means were separated by Least Significance Difference. Statements of significance were based on P-levels as noted. All experiments where repeated twice and a representative experiment is shown in each figure.

\section{Results and Discussion}

Endocannabinoid receptor CB1 and endocannabinoid synthetic enzyme mRNAs increase during differentiation of C2C12 skeletal muscle cells The $\mathrm{C} 2 \mathrm{C} 12$ mouse myoblast cell line is a wellestablished model system for studying myogenesis. $\mathrm{C} 2 \mathrm{C} 12$ cells were cultured in a proliferation media and 


\section{Endocannabinoids regulate skeletal muscle}

European Journal Translational Myology 2010; 1 (4): 167-179

induced to differentiate by switching to a

proliferating $(0 \mathrm{~h})$ or differentiated cells at $24 \mathrm{~h}, 48 \mathrm{~h}$, differentiation media. Total RNA was isolated from $72 \mathrm{~h}$, or $96 \mathrm{~h}$ after switching to a differentiation media
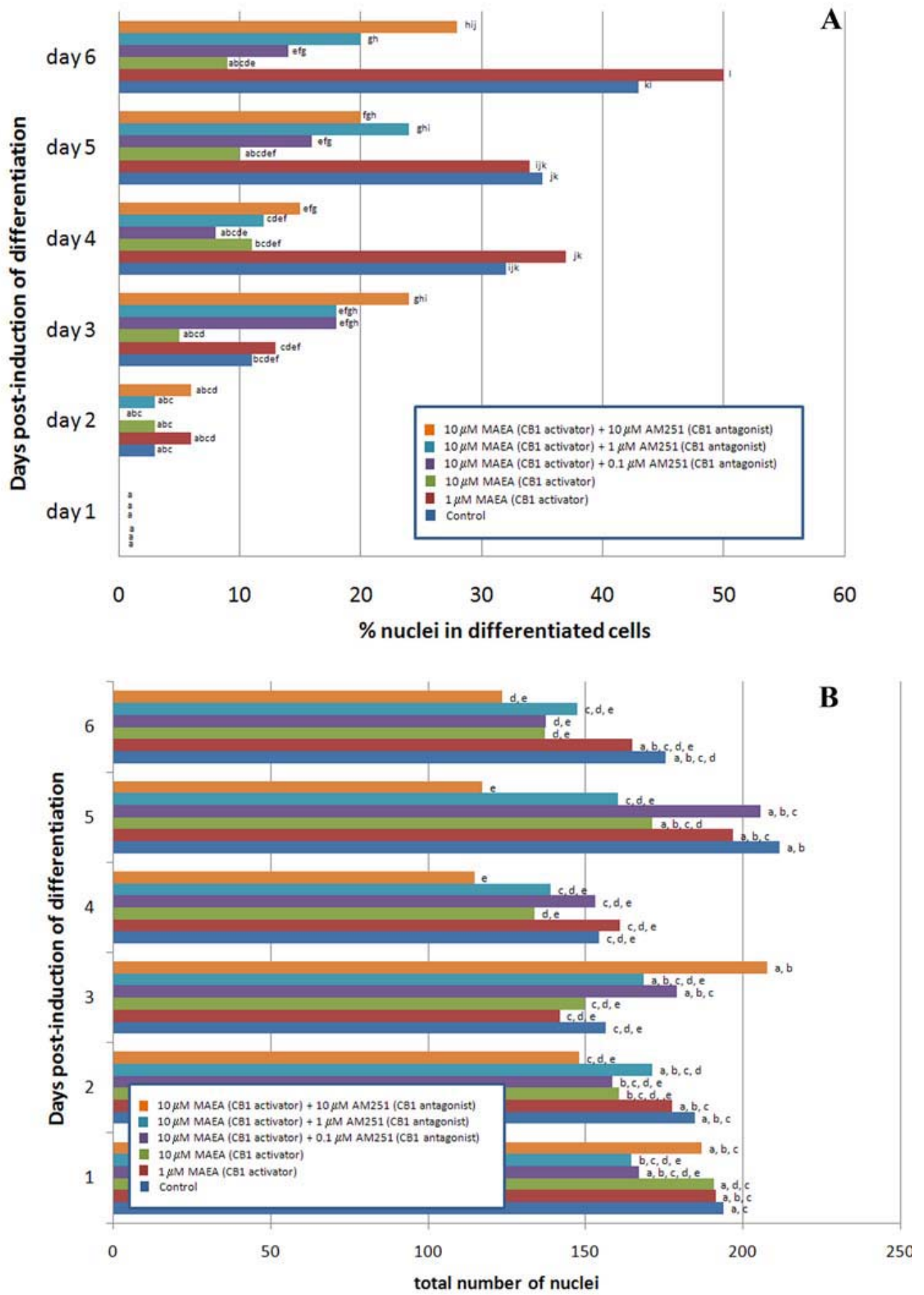

Fig 2. Cannabinoids inhibit differentiation and myofiber formation in C2C12 cultures. A) MAEA treatment inhibits C2C12 myoblast differentiation. C2C12 skeletal muscle cells were cultured in a proliferation media and induced to differentiate by switching to a differentiation media containing 1 or $10 \mu M$ MAEA. Addition of MAEA at 10 $\mu m$ significantly inhibited differentiation. Administration of the CB1 antagonist AM251 blocked the differentiation-inhibitory effects of MEAE. (MSE=1.8); B) Effects of MAEA and/or AM251 on total cell number. There was a loss of total nuclei upon addition of MAEA, but this loss alone would not contribute to the majority of reduction of nuclei in differentiated cells (MSE=10.1); 


\section{Endocannabinoids regulate skeletal muscle}

European Journal Translational Myology 2010; 1 (4): 167-179

and assayed by RT-PCR. Myogenin mRNA

differentiated for 72 and $96 \mathrm{~h}$ (Figure 1A). As expression was significantly elevated in cells myogenin is a differentiation specific mRNA $[42,48]$,
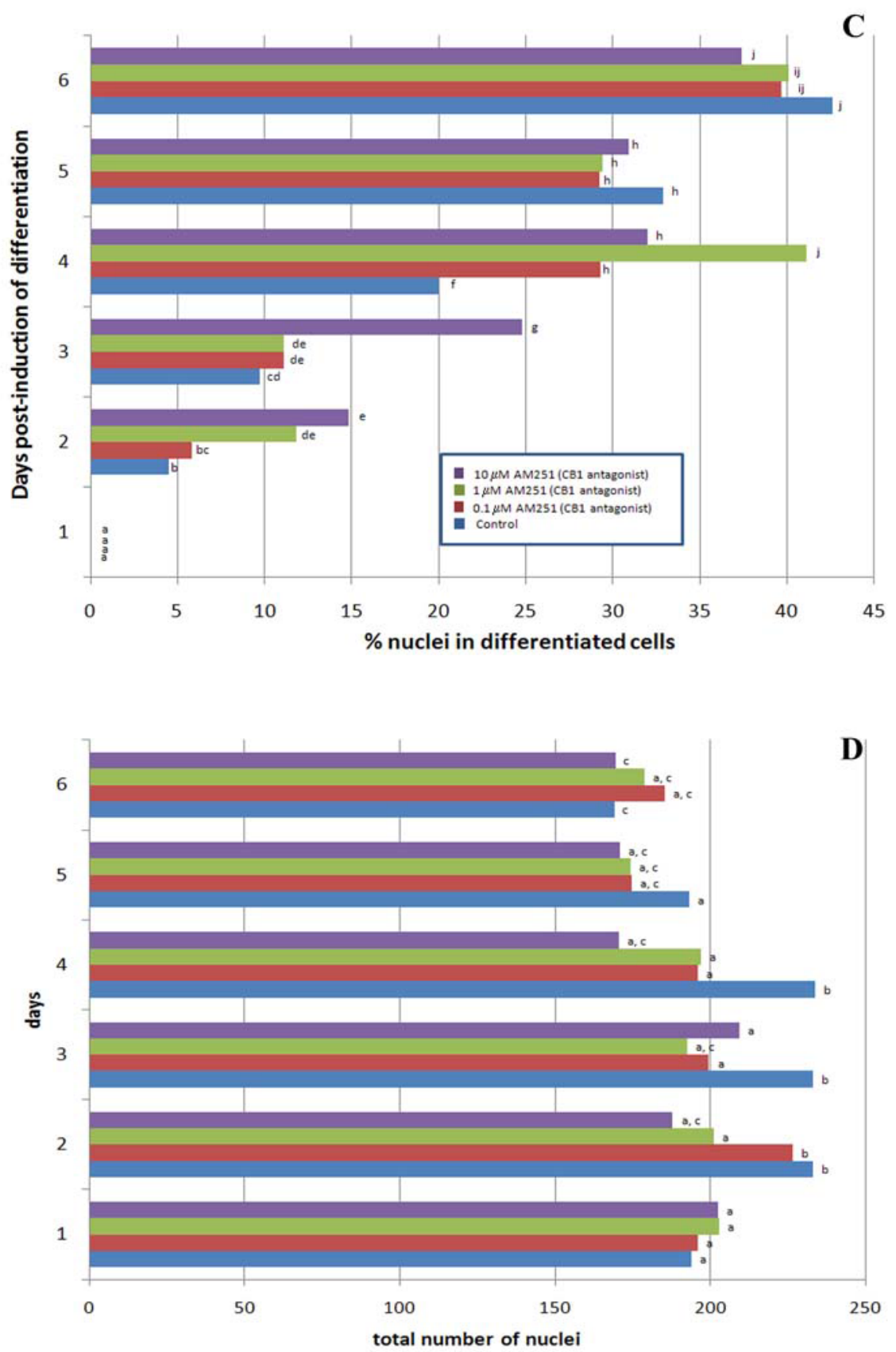

C) Effects of AM251 on myoblast differentiation Addition of AM251 significantly stimulated premature differentiation in C2C12 cells. Five days post-differentiation, significant differences in differentiation were no longer detectable (MSE = 2.1); D) Effects of AM251 on total cell number. Loss of total nuclei number could not solely account for the effects of AM251 on differentiation observed in $C$ (MSE=8.0); $n=6$ for each mean. Means with different superscripts differ $(p<0.01)$. 

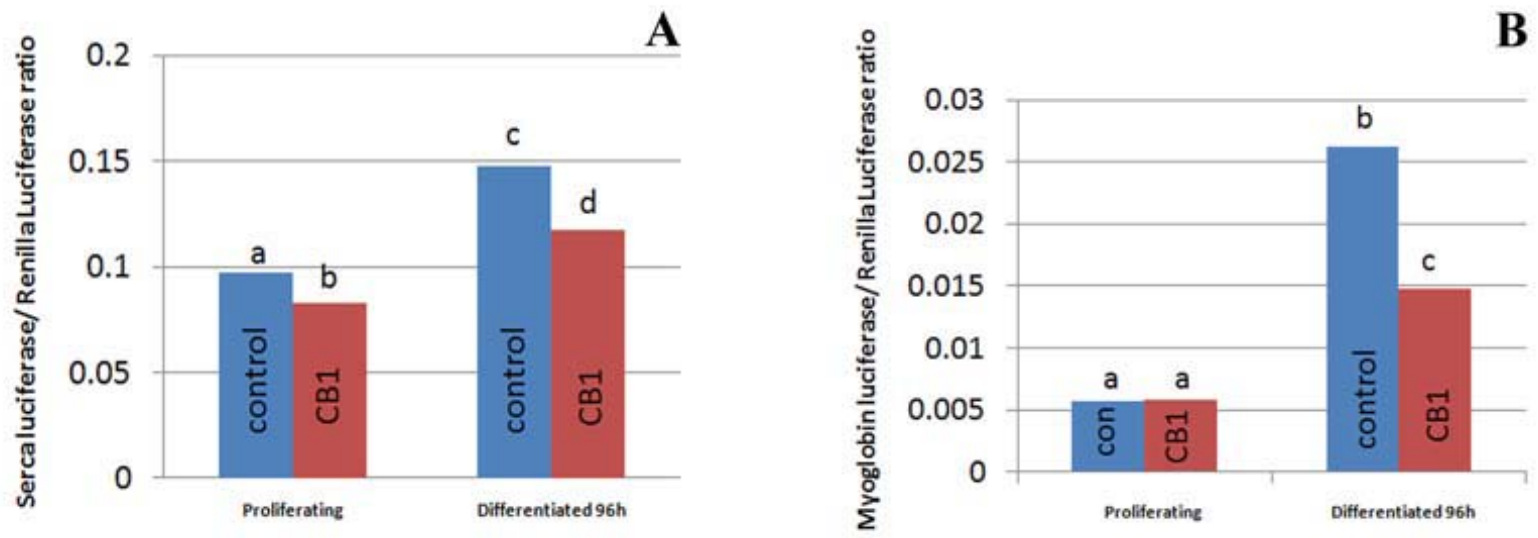

Fig 3. CB1 ectopic expression inhibits C2C12 differentiation. A CB1 receptor expression construct was cotransfected with a slow (Myoglobin-Luciferase) or fast (Sercal-Luciferase) fiber, differentiation-specific reporter gene into proliferating C2C12 cells. Cells were allowed to proliferate for 24 hrs or switched to differentiation medium for 96 hrs. Myoglobin or SERCA luciferase values were normalized for transfection efficiency (co-transfection of pRL-SV40 Renilla luciferase). Ectopic CB1 over-expression inhibited differentiation of C2C12 cells as indicated by the significantly decreased sercal-luciferase (3A) and myoglobin-luciferase (3B) activity. $(A, M S E=0.0018 ; B, M S E=0.00014) ; n=4$ for each mean. Means with different superscripts differ significantly $(p<0.01)$.

this demonstrates that terminal myofiber differentiation was occurring in these cells at these time points. $C B 1$ mRNA expression was significantly up-regulated 24 , 72 and $96 \mathrm{~h}$ post differentiation (Figure 1B). In contrast, $C B 2$ mRNA expression was significantly down-regulated upon terminal differentiation of $\mathrm{C} 2 \mathrm{C} 12$ cells (Figure 1C). In addition, the mRNA expression of the endocannabinoid synthetic enzyme $D A G L a$ was significantly increased following $\mathrm{C} 2 \mathrm{C} 12$ differentiation for 48, 72 and $96 \mathrm{~h}$ (Figure 1D). Nape $P L D$, another endocannabinoid synthetic enzyme, was significantly up-regulated at 24 and $96 \mathrm{~h}$ postinduction of differentiation (Figure 1E). However, the endocannabinoid degradative enzyme $M A G L$ was significantly decreased 24, 48, 72 and $96 \mathrm{~h}$ post differentiation (Figure 1F). CB1 receptors have been detected in skeletal muscle [30]. Our results expand on this observation to demonstrate that expression of the endocannabinoid family is tightly related to myogenic differentiation in vitro, and suggest that the endocannabinoid family might play a role in the functional control of differentiation.

Cannabinoids inhibit differentiation and myofiber formation in C2C12 cultures

MAEA, a synthetic stable activator of CB1, was added to the differentiation media of $\mathrm{C} 2 \mathrm{C} 12$ skeletal muscle cells. In the control treated cells, the percent of differentiated cells as measured by GEIMSA staining, was significantly elevated 3 days post-initiation of differentiation and reached a peak of $42 \% 6$ days postdifferentiation (Figure 2A). Addition of $1 \mu \mathrm{m}$ MAEA had no effect on the progression of differentiation. In contrast, addition of MAEA at $10 \mu \mathrm{m}$ significantly inhibited differentiation, with a maximum differentiation at approximately $10 \%$. To further examine the specificity of the MAEA-mediated inhibition, a CB1 specific antagonist (AM251) was added to the differentiation media in addition to $10 \mu \mathrm{m}$ MAEA. Administration of the CB1 antagonist AM251 at concentration 1 and $10 \mu \mathrm{M}$ significantly blocked the effects of cannabinoid ligands (MAEA $10 \mu \mathrm{M}$ in media) on myoblasts at day 6 after changing to differentiation media. (Figure 2A). To analyze for non-specific cell toxic effects of MAEA, total cell number was also examined. There was some loss of total nuclei upon addition of MAEA, but this loss alone would not contribute to the majority of reduction in nuclei within differentiated cells (Figure 2B). In another set of experiments, the role of endogenous cannabinoids on $\mathrm{C} 2 \mathrm{C} 12$ myoblast differentiation was examined by addition of AM251 to differentiation media. Addition of AM251 significantly stimulated premature differentiation in $\mathrm{C} 2 \mathrm{C} 12$ cells. However, this stimulation was transient in nature as by 5 days post-differentiation, the stimulation was no longer detectable (Figure 2C). There was some loss of total nuclei upon addition of AM251, but the levels could not account for the differences in differentiation (Figure 2D). Further evidence that endogenous endocannabinoids can regulate $\mathrm{C} 2 \mathrm{C} 12$ myoblast differentiation was demonstrated by transient cotransfection of a CB1 receptor expression construct with slow or fast fiber, differentiation-specific reporter gene (serca1-luciferase:fast fiber; or myoglobinluciferase:slow fiber) into proliferating $\mathrm{C} 2 \mathrm{C} 12$ cells. 
A

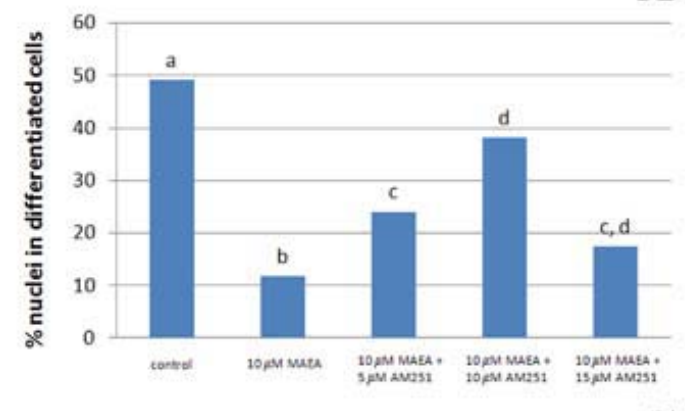

C

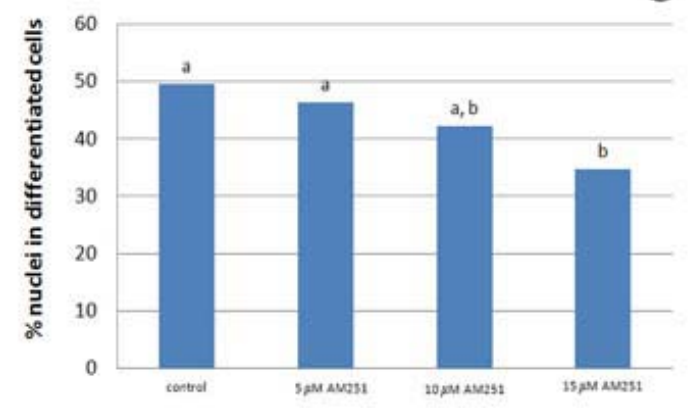

B

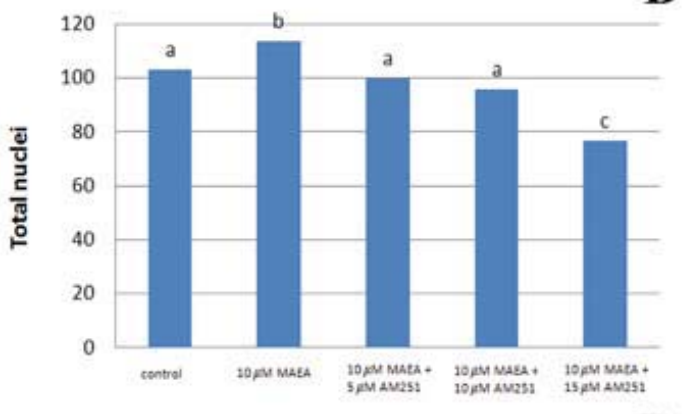

D

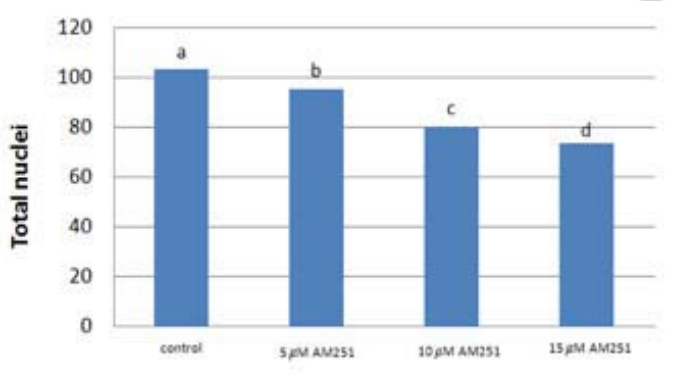

Fig 4. Cannabinoids inhibit differentiation and myofiber formation in primary muscle cell cultures. MAEA was added to the differentiation media of primary myoblast cultures. At 96 hours after the initiation of differentiation, MAEA addition significantly inhibited myoblast differentiation and myofiber formation (A). AM251 significantly blocked the effects of MAEA on primary myoblast differentiation (A; MSE=2.38). Addition of MAEA resulted in increased cell number (B; MSE=2.85). Addition of 5 or $10 \mu M$ AM251 did not have an effect on primary muscle cell differentiation. $15 \mu M$ AM251 inhibited primary muscle cell differentiation (C; MSE=3.05). Addition of AM251 resulted in decreased total cell number (D; MSE=2.94); $n=6$ for each mean. Means with different superscripts differ $(p<0.01)$.

C2C12 cells express both of these expression constructs in a differentiation-specific fashion [41]. Comparing myoglobin or SERCA luciferase values normalized for transfection efficiency (co-transfection of pRL-SV40 Renilla luciferase), it was observed that ectopic CB1 over-expression inhibited differentiation of $\mathrm{C} 2 \mathrm{C} 12$ cells (Figures $3 \mathrm{~A}$ and $3 \mathrm{~B}$ ).

These results demonstrate that in the clonal myoblast cell line $\mathrm{C} 2 \mathrm{C} 12$, cannabinoids can inhibit myoblast differentiation and myofiber formation. Intriguingly, the expression pattern demonstrated above shows that these differentiation-inhibiting factors are expressed when the cells are in the act of differentiation. These novel results explain why a function of the endocannabinoid family could be to halt or slow differentiation as it is occurring.

Cannabinoids inhibit differentiation and myofiber formation in primary muscle cell cultures

To further examine the action of cannabinoids in primary myogenic cells derived from neonatal muscles, MAEA was added to differentiation media of primary myoblast cultures. At 96 hours after the initiation of differentiation, similar to the $\mathrm{C} 2 \mathrm{C} 12$ cultures, MAEA addition significantly inhibited myoblast differentiation and myofiber formation (Figure 4A). AM251 significantly blocked the effects of MAEA on primary myoblast differentiation (Figure $4 \mathrm{~A})$. In contrast to the $\mathrm{C} 2 \mathrm{C} 12$ cultures, addition of MAEA resulted in increased cell number (Figure 4B). Addition of $10 \mu \mathrm{M}$ AM251 did not have an effect on primary muscle cell differentiation; however high concentration AM251 $(15 \mu \mathrm{M})$ can inhibit primary muscle cell differentiation (Figure 4C). Addition of AM251 resulted in decreased cell number (Figure 4D). In summary, cannabinoids can inhibit differentiation in primary myoblast cultures similarly in $\mathrm{C} 2 \mathrm{C} 12$ cells.

Cannabinoids regulates satellite cell proliferation in isolated skeletal muscle single fiber culture

As we have demonstrated, cannabinoids are synthesized by differentiating myoblasts, and these cannabinoids seem to act to inhibit differentiation. This provides evidence for the hypothesis that cannabinoids produced by the differentiated fiber act to reduce the differentiation of surrounding myoblasts. Isolated 


\section{Endocannabinoids regulate skeletal muscle}

European Journal Translational Myology 2010; 1 (4): 167-179

myofibers provide a good model to study the activation, proliferation, and differentiation of satellite
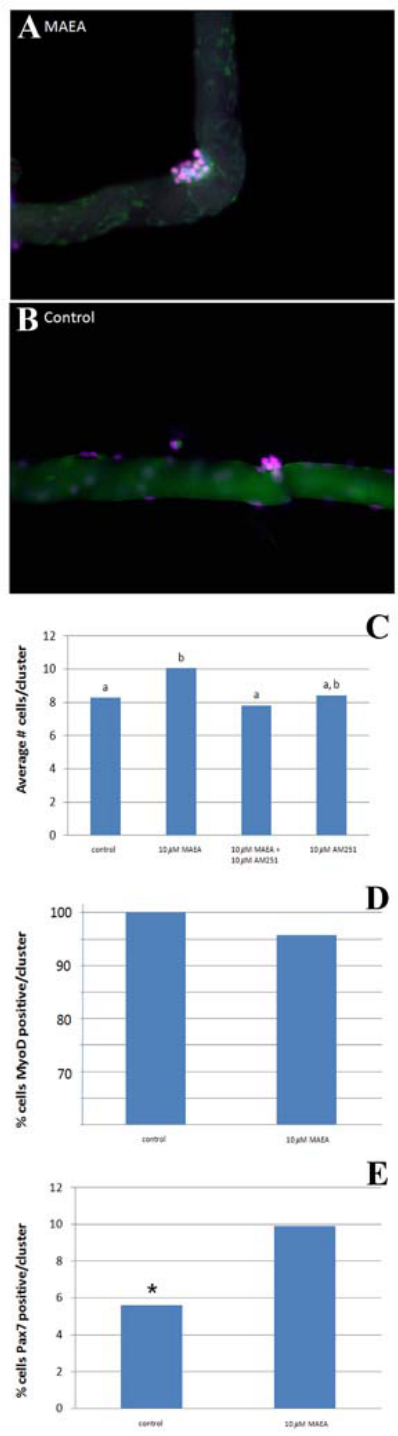

Fig 5. Cannabinoids stimulate proliferation of and inhibits determination of satellite cells. Representative pictures of single muscle fiber cultures following immunohistochemistry for Pax7(blue) and MyoD(pink) after treatment with MAEA (A) or control (B). Nuclei were counterstained with DAPI. The number of nuclei in each cluster was significantly increased by MAEA treatment (C). This increase was blocked by AM251 (C; MSE=0.64). Although not significant, there was a 5-10\% cell decrease in MyoD positive cells/cluster following $M A E A$ treatment $(D ; M S E=0.12)$. There was approximately a 2-fold increase in Pax7 positive cells/cluster following MAEA treatment (E; MSE = .056); $n=50$ for each mean. Means with different superscripts, or with/without asterisks, differ $(p<0.01)$. cells in their native position beneath the basal lamina. This model preserves the potentially important interactions between satellite cells and multi-nucleated myofibers (Figures 5A and 5B). Myofibers were isolated from the extensor digitorum longus (EDL) muscle of adult mice and cultured in suspension growth medium with or without $10 \mu \mathrm{M}$ MAEA. Satellite cells typically form clusters of myoblast progenies on isolated myofibers after several days of suspended culture. Addition of MAEA resulted in a significant increase in the numbers of nuclei in each cluster (Figure 5C). This suggests an endocannabinoid mediated stimulation of satellite cell proliferation. Addition of AM251 inhibited this MAEA mediated effect on cell number per cluster (Figure 5C). MyoD is expressed in activated satellite cells and an early marker of myogenic differentiation [27]. MyoD is typically highly expressed in myogenic cells entering the differentiation program and in differentiated myocytes and myotubes $[27,47]$. There was a trend for a reduced number of MyoD positive cells following MAEA treatment (Figure 5D). In adult muscle, $\operatorname{Pax} 7$ is expressed by both quiescent and activated satellite cells, but not in differentiated myocytes or myotubes $[25,40]$. We observed an increased number of Pax7 positive cells in MAEA treated cultures (Figure 5E). Our results suggest that cannabinoids can stimulate proliferation and/or inhibit differentiation of satellite cells, and support the hypothesis, derived from our in vitro expression data that the ECS synthesized by differentiated muscle fibers might act to ensure a population of myogenic stem cells for future regeneration and growth. While some recent studies have shown that cannabinoids regulate proliferation and differentiation of many cell types $[13,19,20,34,38,46]$, these results are the first demonstration of their role in regulating skeletal muscle myoblasts.

The endocannabinoid family is developmentally expressed in skeletal muscle in vivo

The mRNA expression of the endocannabinoid family was analyzed in mice gastrocnemius muscles of different developmental ages. The expressions of CB1, $D A G L a, N A P E-P L D$ and $M A G L$ were significantly decreased with increasing age (Figure 6). In contrast $C B 2$ mRNA expression was not significantly changed with development (Figure 6B). The dynamic expression of these genes involved in the ECS suggests a role for these factors in postnatal muscle growth and aging.

CB1 $\mathrm{mRNA}$ expression is greater in fast than slow muscles

Gastrocnemius, soleus and tibialis anterior muscles were dissected and pooled from 5 week old male mice. These muscles were used for RT-PCR analysis of $C B 1$ mRNA expression. The levels of $C B 1 \mathrm{mRNA}$ were 


\section{Endocannabinoids regulate skeletal muscle}

European Journal Translational Myology 2010; 1 (4): 167-179

significantly greater in the tibialis anterior muscle

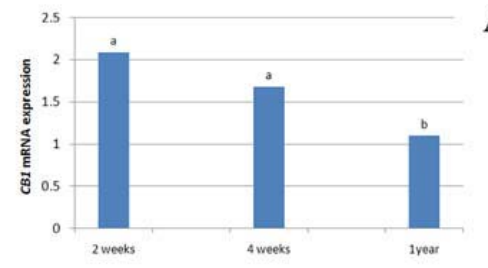

A
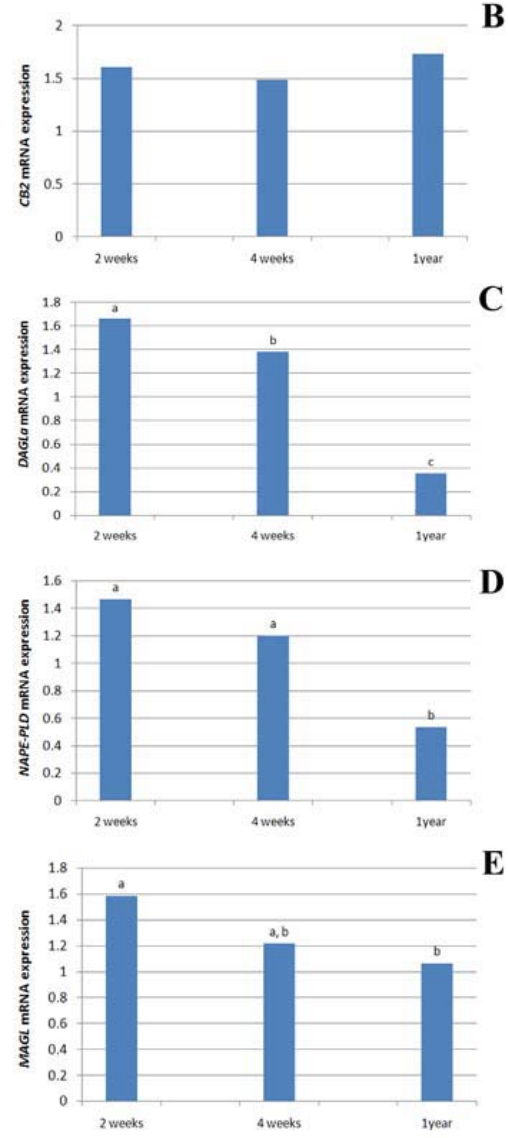

Fig 6. Expression of the endocannibinoid family $m R N A$ is developmentally regulated in skeletal muscle. Gastrocnemius muscles were dissected from $2 w, 4 w$ and 1 year old mice. The endocannabinoid family $m R N A$ was measured in these muscles using RT-PCR. (A) CB1 $m R N A$ expression was significantly downregulated with increasing age. (MSE $=0.12)$; (B) CB2 $m R N A$ expression did not change with increasing age. (MSE = 0.17); (C) The endocannabinoid synthetic enzyme DAGLa expression significantly decreased upon aging. (MSE=0.076); (D) The endocannabinoid synthetic enzyme NAPE-PLD expression was significantly decreased with increasing age. $(M S E=0.12) ; \quad(E)$ The expression of the endocannibinoid degradative enzyme MAGL was significantly decreased as the mice got 1 year old. $(M S E=0.17) . n=4$ for each mean. Means with different superscripts differ $(p<0.01)$. (primarily fast-type) than in the gastrocnemius (mixed), which was significantly greater than that observed in the soleus muscle (primarily slow-type) (Figure 7).

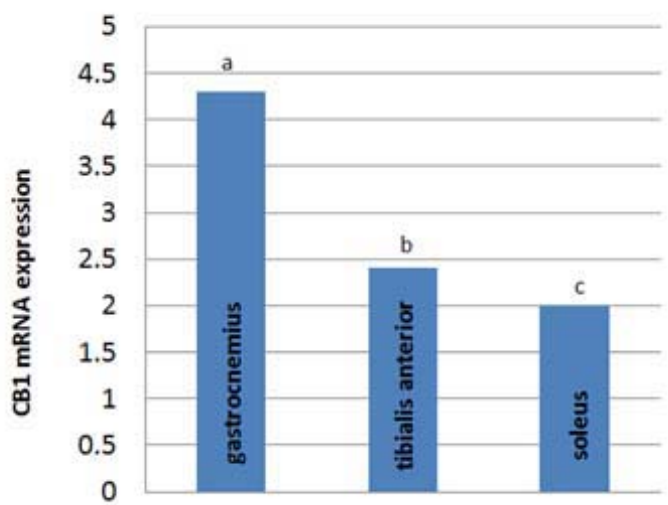

Fig 7. CB1 expression is greatest in fast-type skeletal muscles Gastrocnemius, soleus and tibialis anterior muscles were dissected and pooled from 5 week old male mice. These muscles were used for RT-PCR analysis of $C B 1 \mathrm{mRNA}$ expression. The levels of CB1 $m R N A$ were significantly greater in the tibialis anterior muscle (primarily fast-type) than in the gastrocnemius (mixed), which was significantly greater than that observed in the soleus muscle (primarily slow-type). (MSE=0.00781). $\quad n=4$ for each mean. Means with different superscripts differ $(p<0.05)$

\section{CB1 regulates muscle fiber metabolism in vivo}

The above studies all examined the role of the cannabinoids during myogenesis by introducing cannabinoids to the proliferating myoblast and determining effects on differentiation. Yet, as determined by the expression studies, cannabinoids and their receptors are made by differentiated fibers. In order to determine what effect the cannabinoid family has on the differentiated fiber a CB1-receptor expression construct was co-electroporated with reporter gene vectors (Sercal-luciferase and myoglobin-luciferase) into the soleus and gastrocnemius muscle of mice. In contrast to in vitro transfections which target proliferating myoblasts, these electroporations target differentiated fibers $[1,17,45]$. Ectopic expression of CB1 in these muscles stimulated fast fiber-specific, and inhibited slow fiber specific, reporter activities in vivo (Figures 8A and $8 \mathrm{~B})$. As skeletal muscle metabolism is associated with fiber types, these results suggest that the cannabinoids can regulate the metabolism in adult skeletal muscle. It is well-known that slow/oxidative muscle fibers play a very important role in regulating whole-body metabolism [22,49]. Recently, a study showed that an 

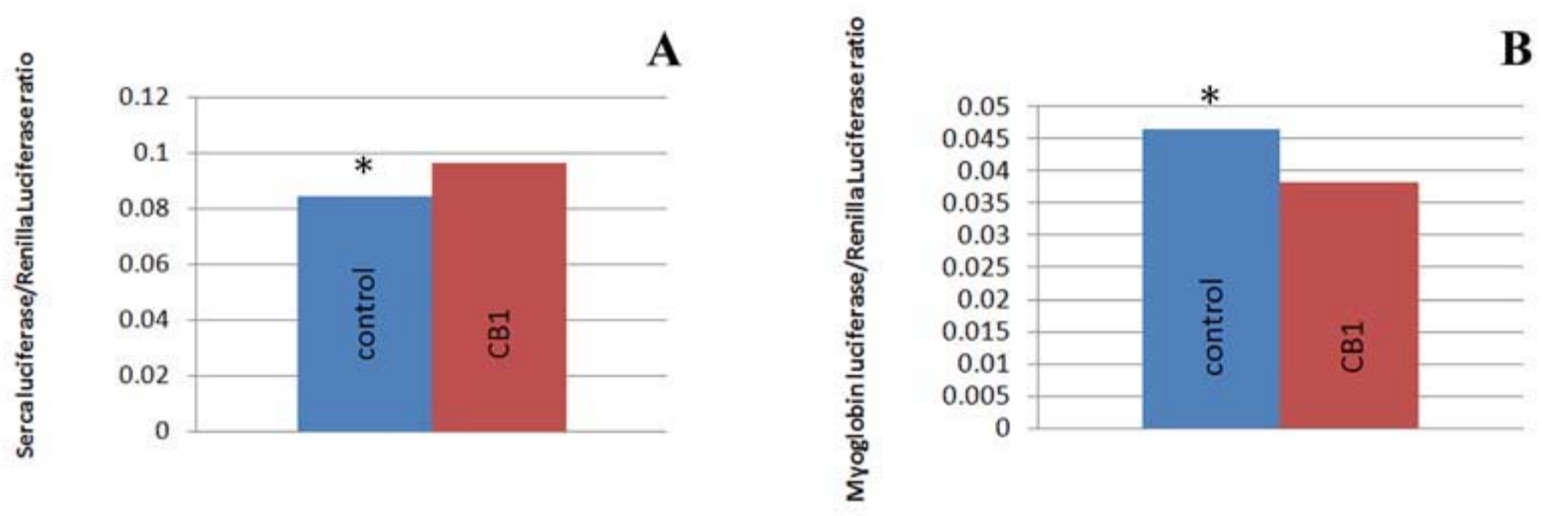

Fig 8. CB1 regulates muscle fiber metabolism in vivo. A CB1-receptor expression construct was co-electroporated with reporter gene vectors (Sercal-luciferase or myoglobin-luciferase) into the gastrocnemius muscles of mice. Ectopic expression of CB1 in these muscles stimulated fast fiber-specific reporter $(A ; M S E=0.00399)$ activity and inhibited slow fiber specific in vivo $(B ; M S E=0.0014) . n=5$ for each mean. Asterisk indicates a significant difference $(p<0.01)$.

increase of fast/glycolytic muscle mass can regress obesity by altering fatty acid oxidation in remote tissues [23]. Our results suggest that ectopic ECS treatment could help fight obesity by regulating muscle metabolism in a similar fashion. In summary, our findings contribute to the understanding of the role of endocannabinoid system in skeletal muscle metabolism and muscle oxygen consumption, and also help to explain the effects of peripheral endocannabinoid system on whole-body energy balance. In addition, our results suggest caution for ECS use in situations where muscle development is currently ongoing, or regeneration might be needed.

\section{Corresponding Author}

Kevin Hannon, Department of Basic Medical Sciences, Purdue University, West Lafayette, IN 47907, USA; Email: Hannonk@purdue.edu

\section{References}

[1] Alzghoul MB, Gerrard D, Watkins BA, Hannon K. Ectopic expression of IGF-I and Shh by skeletal muscle inhibits disuse-mediated skeletal muscle atrophy and bone osteopenia in vivo. Faseb J 2004; 18: 221-223.

[2] Bellocchio L, Lafenetre P, Cannich A, Cota D, Puente N, Grandes P, Chaouloff F, Piazza PV, Marsicano G. Bimodal control of stimulated food intake by the endocannabinoid system. Nat Neurosci 13: 281-283.

[3] Beltramo M, Stella N, Calignano A, Lin SY, Makriyannis A, Piomelli D. Functional role of high-affinity anandamide transport, as revealed by selective inhibition. Science 1997; 277: 10941097.
[4] Bisogno T, Maurelli S, Melck D, De Petrocellis L, Di Marzo V. Biosynthesis, uptake, and degradation of anandamide and palmitoylethanolamide in leukocytes. J Biol Chem 1997; 272: 3315-3323.

[5] Chin ER, Olson EN, Richardson JA, Yang Q, Humphries C, Shelton JM, Wu H, Zhu W, BasselDuby R, Williams RS. A calcineurin-dependent transcriptional pathway controls skeletal muscle fiber type. Genes Dev 1998; 12: 2499-2509.

[6] Colberg SR, Simoneau JA, Thaete FL, Kelley DE. Skeletal muscle utilization of free fatty acids in women with visceral obesity. J Clin Invest 1995; 95: 1846-1853.

[7] Cota D, Marsicano G, Tschop M, Grubler Y, Flachskamm C, Schubert M, Auer D, Yassouridis A, Thone-Reineke C, Ortmann S, Tomassoni F, Cervino C, Nisoli E, Linthorst AC, Pasquali R, Lutz B, Stalla GK, Pagotto U. The endogenous cannabinoid system affects energy balance via central orexigenic drive and peripheral lipogenesis. J Clin Invest 2003; 112: 423-431.

[8] Cota D WS. The role of the endocannabinoid system in the regulation of energy homeostasis. Curr Opin Endocrinol Diabetes 2005; 12: 338351.

[9] Cote M, Matias I, Lemieux I, Petrosino S, Almeras N, Despres JP, Di Marzo V. Circulating endocannabinoid levels, abdominal adiposity and related cardiometabolic risk factors in obese men. Int J Obes (Lond) 2007; 31: 692-699.

[10] Cravatt BF, Giang DK, Mayfield SP, Boger DL, Lerner RA, Gilula NB. Molecular characterization of an enzyme that degrades 


\section{Endocannabinoids regulate skeletal muscle}

European Journal Translational Myology 2010; 1 (4): 167-179

neuromodulatory fatty-acid amides. Nature 1996; 384: 83-87.

[11] Dani M, Guindon J, Lambert C, Beaulieu P. The local antinociceptive effects of paracetamol in neuropathic pain are mediated by cannabinoid receptors. Eur J Pharmacol 2007; 573: 214-215.

[12] de Kloet AD, Woods SC. Minireview: Endocannabinoids and their receptors as targets for obesity therapy. Endocrinology 2009; 150: 2531-2536.

[13] DeMorrow S, Francis H, Gaudio E, Ueno Y, Venter J, Onori P, Franchitto A, Vaculin B, Vaculin S, Alpini G. Anandamide inhibits cholangiocyte hyperplastic proliferation via activation of thioredoxin 1/redox factor 1 and AP1 activation. Am J Physiol Gastrointest Liver Physiol 2008; 294: G506-519.

[14] Deutsch DG, Chin SA. Enzymatic synthesis and degradation of anandamide, a cannabinoid receptor agonist. Biochem Pharmacol 1993; 46: 791-796.

[15] Di Marzo V, Matias I. Endocannabinoid control of food intake and energy balance. Nat Neurosci 2005; 8: 585-589.

[16] Dinh TP, Freund TF, Piomelli D. A role for monoglyceride lipase in 2-arachidonoylglycerol inactivation. Chem Phys Lipids 2002; 121: 149158.

[17] Eash J, Olsen A, Breur G, Gerrard D, Hannon K. FGFR1 inhibits skeletal muscle atrophy associated with hindlimb suspension. BMC Musculoskelet Disord 2007; 8: 32.

[18] Gaetani S, Kaye WH, Cuomo V, Piomelli D. Role of endocannabinoids and their analogues in obesity and eating disorders. Eat Weight Disord 2008; 13: e42-48.

[19] Galve-Roperh I, Rueda D, Gomez del Pulgar T, Velasco G, Guzman M. Mechanism of extracellular signal-regulated kinase activation by the $\mathrm{CB}(1)$ cannabinoid receptor. Mol Pharmacol 2002; 62: 1385-1392.

[20] Giuliano M, Calvaruso G, Pellerito O, Portanova P, Carlisi D, Vento R, Tesoriere G. Anandamideinduced apoptosis in Chang liver cells involves ceramide and JNK/AP-1 pathway. Int J Mol Med 2006; 17: 811-819.

[21] Hanus L, Abu-Lafi S, Fride E, Breuer A, Vogel Z, Shalev DE, Kustanovich I, Mechoulam R. 2arachidonyl glyceryl ether, an endogenous agonist of the cannabinoid CB1 receptor. Proc Natl Acad Sci U S A 2001; 98: 3662-3665.

[22] Hawley JA, Zierath JR. Integration of metabolic and mitogenic signal transduction in skeletal muscle. Exerc Sport Sci Rev 2004; 32: 4-8.
[23] Izumiya Y, Hopkins T, Morris C, Sato K, Zeng L, Viereck J, Hamilton JA, Ouchi N, LeBrasseur NK, Walsh K. Fast/Glycolytic muscle fiber growth reduces fat mass and improves metabolic parameters in obese mice. Cell Metab 2008; 7 : 159-172.

[24] Kahn BB, Pedersen O. Suppression of GLUT4 expression in skeletal muscle of rats that are obese from high fat feeding but not from high carbohydrate feeding or genetic obesity. Endocrinology 1993; 132: 13-22.

[25] Kassar-Duchossoy L, Giacone E, Gayraud-Morel B, Jory A, Gomes D, Tajbakhsh S. Pax3/Pax7 mark a novel population of primitive myogenic cells during development. Genes Dev 2005; 19: 1426-1431.

[26] Kirkham TC, Tucci SA. Endocannabinoids in appetite control and the treatment of obesity. CNS Neurol Disord Drug Targets 2006; 5: 272-292.

[27] Koishi K, Zhang M, McLennan IS, Harris AJ. MyoD protein accumulates in satellite cells and is neurally regulated in regenerating myotubes and skeletal muscle fibers. Dev Dyn 1995; 202: 244254.

[28] Maldonado R, Valverde O, Berrendero F. Involvement of the endocannabinoid system in drug addiction. Trends Neurosci 2006; 29: 225232.

[29] Matias I, Di Marzo V. Endocannabinoids and the control of energy balance. Trends Endocrinol Metab 2007; 18: 27-37.

[30] Matias I, Gonthier MP, Orlando P, Martiadis V, De Petrocellis L, Cervino C, Petrosino S, Hoareau L, Festy F, Pasquali R, Roche R, Maj M, Pagotto U, Monteleone P, Di Marzo V. Regulation, function, and dysregulation of endocannabinoids in models of adipose and beta-pancreatic cells and in obesity and hyperglycemia. J Clin Endocrinol Metab 2006; 91: 3171-3180.

[31] Mechoulam R, Ben-Shabat S, Hanus L, Ligumsky M, Kaminski NE, Schatz AR, Gopher A, Almog S, Martin BR, Compton DR, et al. Identification of an endogenous 2-monoglyceride, present in canine gut, that binds to cannabinoid receptors. Biochem Pharmacol 1995; 50: 83-90.

[32] Okamoto Y, Morishita J, Tsuboi K, Tonai T, Ueda N. Molecular characterization of a phospholipase D generating anandamide and its congeners. J Biol Chem 2004; 279: 5298-5305.

[33] Osei-Hyiaman D, DePetrillo M, Pacher P, Liu J, Radaeva S, Batkai S, Harvey-White J, Mackie K, Offertaler L, Wang L, Kunos G. Endocannabinoid activation at hepatic CB1 receptors stimulates fatty acid synthesis and 


\section{Endocannabinoids regulate skeletal muscle}

European Journal Translational Myology 2010; 1 (4): 167-179

contributes to diet-induced obesity. J Clin Invest 2005; 115: 1298-1305.

[34] Paradisi A, Pasquariello N, Barcaroli D, Maccarrone M. Anandamide regulates keratinocyte differentiation by inducing DNA methylation in a CB1 receptor-dependent manner. J Biol Chem 2008; 283: 6005-6012.

[35] Pedersen SB, Borglum JD, Schmitz O, Bak JF, Sorensen NS, Richelsen B. Abdominal obesity is associated with insulin resistance and reduced glycogen synthetase activity in skeletal muscle. Metabolism 1993; 42: 998-1005.

[36] Piomelli D. The molecular logic of endocannabinoid signalling. Nat Rev Neurosci 2003; 4: 873-884.

[37] Porter AC, Sauer JM, Knierman MD, Becker GW, Berna MJ, Bao J, Nomikos GG, Carter P, Bymaster FP, Leese AB, Felder CC. Characterization of a novel endocannabinoid, virodhamine, with antagonist activity at the CB1 receptor. J Pharmacol Exp Ther 2002; 301: 10201024.

[38] Rajesh M, Mukhopadhyay P, Hasko G, Huffman JW, Mackie K, Pacher P. CB2 cannabinoid receptor agonists attenuate TNF-alpha-induced human vascular smooth muscle cell proliferation and migration. Br J Pharmacol 2008; 153: 347357.

[39] Rodriguez de Fonseca F, Del Arco I, BermudezSilva FJ, Bilbao A, Cippitelli A, Navarro M. The endocannabinoid system: physiology and pharmacology. Alcohol Alcohol 2005; 40: 2-14.

[40] Seale P, Ishibashi J, Scime A, Rudnicki MA. Pax7 is necessary and sufficient for the myogenic specification of $\mathrm{CD} 45+: \mathrm{Sca} 1+$ stem cells from injured muscle. PLoS Biol 2004; 2: E130.

[41] Shi H, Gerrard D, Grant A, Bidwell C, Hannon K. Modulation of Skeletal Muscle Fiber Growth and
Specialization by Mitogen-activated Protein Kinase Pathways. Purdue Ph. D dissertation 2006:

[42] Smith CK, 2nd, Janney MJ, Allen RE. Temporal expression of myogenic regulatory genes during activation, proliferation, and differentiation of rat skeletal muscle satellite cells. J Cell Physiol 1994; 159: 379-385.

[43] Stella N, Schweitzer P, Piomelli D. A second endogenous cannabinoid that modulates longterm potentiation. Nature 1997; 388: 773-778.

[44] Swoap SJ, Hunter RB, Stevenson EJ, Felton HM, Kansagra NV, Lang JM, Esser KA, Kandarian SC. The calcineurin-NFAT pathway and muscle fiber-type gene expression. Am J Physiol Cell Physiol 2000; 279: C915-924.

[45] Taylor J, Babbs CF, Alzghoul MB, Olsen A, Latour M, Pond AL, Hannon K. Optimization of ectopic gene expression in skeletal muscle through DNA transfer by electroporation. BMC Biotechnol 2004; 4: 11.

[46] Turco MY, Matsukawa K, Czernik M, Gasperi V, Battista N, Della Salda L, Scapolo PA, Loi P, Maccarrone M, Ptak G. High levels of anandamide, an endogenous cannabinoid, block the growth of sheep preimplantation embryos by inducing apoptosis and reversible arrest of cell proliferation. Hum Reprod 2008; 23: 2331-2338.

[47] Yablonka-Reuveni Z, Paterson BM. MyoD and myogenin expression patterns in cultures of fetal and adult chicken myoblasts. J Histochem Cytochem 2001; 49: 455-462.

[48] Yablonka-Reuveni Z, Rivera AJ. Temporal expression of regulatory and structural muscle proteins during myogenesis of satellite cells on isolated adult rat fibers. Dev Biol 1994; 164: 588603.

[49] Zierath JR, Hawley JA. Skeletal muscle fiber type: influence on contractile and metabolic properties. PLoS Biol 2004; 2: e348. 


\section{Endocannabinoids regulate skeletal muscle}

European Journal Translational Myology 2010; 1 (4): 167-179 